\title{
Teores de glicina+ serina total em dietas de baixa proteína bruta para de frangos de corte de 22 a 35 dias de idade
}

[Total glycine+serine level in low crude protein diets of broiler chickens from 22 to 35 days of age]

\author{
C.H.F. Vasconcellos ${ }^{1}$, D.O. Fontes ${ }^{2}$, M.A. Silva ${ }^{2}$, G.S.S. Corrêa ${ }^{3}$, L.J.C. Lara $^{2}$, T.Z.B. Vidal ${ }^{3}$, \\ A.L.C. Machado ${ }^{3}$, I.S. Fernandes ${ }^{5}$ \\ ${ }^{1}$ IFMT- Cuiabá, MT \\ ${ }^{2}$ Escola de Veterinária - UFMG - Belo Horizonte, MG \\ ${ }^{3}$ UFMT - Cuiabá, MT \\ ${ }^{4}$ Alunos de pós-graduação - EV-UFMG - Belo Horizonte, MG \\ ${ }^{5}$ Aluna de iniciação científica - EV-UFMG- Belo Horizonte, MG
}

\begin{abstract}
RESUMO
O experimento foi realizado em delineamento inteiramente ao acaso para avaliar os efeitos de diferentes teores de glicina + serina (gli+ser) total em dietas de baixa proteína bruta (PB) sobre o desempenho e as características de carcaça de frangos de corte de 22 a 35 dias de idade. Foram utilizadas 750 aves distribuídas em cinco tratamentos, cinco repetições e 30 aves por unidade experimental. As aves foram alimentadas até os 21 dias com uma dieta comum de acordo com as exigências. A partir do $21^{\circ}$ dia, as dietas utilizadas continham $17 \%$ de PB e níveis de gli+ser de 1,50; 1,75; 2,00 e 2,25\%; a dieta-controle continha $21 \%$ de PB. O teor de gli+ser teve efeito linear sobre a conversão alimentar e não sobre as demais variáveis de desempenho. Não houve efeito de tratamento sobre os rendimentos de carcaça e cortes. Houve efeito linear decrescente do teor de gli+ser sobre a matéria seca da carcaça.
\end{abstract}

Palavras-chave: frango, aminoácido, desempenho, carcaça

\begin{abstract}
A completely randomized experimental design was carried out to evaluate the effects of total glycine + serine (gly + ser) levels in low crude protein (CP) diets on performance and body composition of male broiler from 22 to 35 days of age (growing phase). A total of 750 broilers were randomly allotted to five treatments and five replicates of 30 chickens per replication. The birds were fed from 1 to 21 days of age, a common diet formulated to meet bird requirements in all nutrients. From 21 days the diets contained 17\% CP and gly+ser levels of 1.50; 1.75; 2.00 and 2.25\%; and a control diet with $21 \% C P$. The gly+ser levels showed linear effect on feed: weight gain ratio during the growing phase. There was no effect of gly+ser level on carcass or main carcass part yields. Increasing levels of gly+ser decreased linearly the carcass dry matter content.
\end{abstract}

Keywords: broiler, amino acid, performance, carcass

\section{INTRODUÇÃO}

$\mathrm{Na}$ avicultura industrial, pequena diferença em aumento de produtividade ou em redução de custos pode contribuir de modo significativo para o aumento da lucratividade do sistema. Atualmente existe grande pressão, não apenas para diminuir os custos da atividade, mas também para reduzir desperdícios e eliminação de elementos poluentes, dentre os quais está o nitrogênio.

A redução da eliminação de nitrogênio na excreta das aves é facilmente conseguida quando se reduz o fornecimento de proteína na dieta. A redução da proteína bruta das dietas nem sempre

Recebido em 22 de novembro de 2010

Aceito em 30 de março de 2011

E-mail: carloshzoo@yahoo.com.br 
está associada ao bom desempenho. Pesquisas sugerem diminuição do ganho de peso, piora da conversão alimentar e aumento do conteúdo de gordura na carcaça, indesejável pelos consumidores (Bregendahl et al., 2002; Sabino et al., 2004).

Alguns trabalhos têm demonstrado que, para se alcançar o nível de desempenho de aves alimentadas com dietas de alta proteína quando se trabalha com níveis proteicos reduzidos, há necessidade de suplementação de aminoácidos não essenciais, além dos essenciais (Kerr e Kidd, 1999; Dean et al., 2006). A adição do aminoácido glicina em dietas de reduzido teor proteico tem efeito benéfico sobre as variáveis de desempenho. Dean et al. (2006) verificaram efeito linear da suplementação de diferentes níveis de glicina a dietas de baixa proteína sobre os parâmetros de desempenho.

Sempre que uma molécula de ácido úrico é excretada, uma molécula de glicina é eliminada. Esse raciocínio tem levado os pesquisadores a acreditar que a exigência de glicina pode ser maior em aves de rápido crescimento e em dietas com excesso de proteína ou em desequilíbrio. Embora a glicina seja sintetizada pelas aves, essa síntese não é rápida o suficiente para satisfazer as necessidades dos tecidos e eliminar todo o excesso de nitrogênio (Tejedor, 2002). Desse modo, existem três pontos conflitantes: a necessidade de manter ótimo retorno econômicoprodutivo da atividade avícola, a manutenção da qualidade e da composição da carcaça de acordo com as exigências do consumidor e, finalmente, a necessidade de levar em conta o fator ambiental diminuindo a excreção de nitrogênio.

Segundo a literatura, a suplementação de Lglicina às dietas de baixa proteína permite maior desempenho das aves que recebem a suplementação comparado àquele das aves suplementadas apenas com aminoácidos essenciais (Dean et al., 2006), mas nem sempre essa suplementação permite desempenho equivalente ao obtido com aves alimentadas com dietas-controle. Nesse sentido, o presente trabalho teve como objetivo avaliar o efeito de diferentes níveis de glicina+serina sobre o desempenho, a composição de carcaça e o rendimento de carcaça e cortes de frangos de corte machos de 22 a 35 dias de idade, alimentados com dietas contendo baixo nível de proteína bruta (PB), bem como comparar o desempenho dessas aves com aquelas alimentadas com uma dieta-controle de alto nível proteico.

\section{MATERIAL E MÉTODOS}

As aves foram alojadas em galpão de alvenaria com piso de concreto, em 25 boxes idênticos de estrutura metálica, com área de $3 \mathrm{~m}^{2}$, forrados com cepilho de madeira, contendo comedouros semiautomáticos e bebedouros tipo copo de pressão, na fase inicial, e um comedouro tubular e um bebedouro pendular, na fase de crescimento para cada unidade experimental. Foi utilizado um termômetro de máxima e mínima, colocado no interior do galpão, para registro diário da temperatura.

Foram utilizados 750 pintos de corte, machos, de linhagem comercial de 22 a 35 dias de idade, distribuídos aleatoriamente em cinco tratamentos e cinco repetições, com 30 aves/boxe (10 aves $\left./ \mathrm{m}^{2}\right)$. As aves foram vacinadas no incubatório de origem contra a doença de Marek e, aos 12 dias de idade, contra a doença de Gumboro, via água de bebida.

Até os 14 dias de idade, as aves receberam aquecimento artificial por uma lâmpada infravermelha por boxe. Durante os primeiros sete dias de alojamento, foi utilizado um bebedouro tipo copo de pressão para cada 30 aves e, a partir do sétimo dia, utilizou-se um bebedouro pendular automático para cada boxe. Este último permaneceu até o período final de criação. $\mathrm{Na}$ fase inicial, foi utilizado um comedouro tubular tipo infantil para cada boxe e, posteriormente, na fase de crescimento, um comedouro do tipo tubular para cada 30 aves. O programa de luz utilizado foi: um a 14 dias, 24 horas de luz; 14 a 35 dias de idade, luz natural. As temperaturas máxima e mínima durante o experimento variaram de $28,4 \pm 7,0^{\circ} \mathrm{C}$ a $14,8 \pm 3,5^{\circ} \mathrm{C}$, para a fase inicial, e entre $28,0 \pm 7,0^{\circ} \mathrm{C}$ e $14,5 \pm 3,0^{\circ} \mathrm{C}$, para a fase de crescimento.

Até os 21 dias de idade, as aves receberam uma dieta comum, contendo $23 \%$ de PB, formulada para atender às exigências nutricionais dos frangos de acordo com Rostagno et al. (2005). A partir dos 21 dias de idade, foram utilizadas cinco dietas, sendo uma dieta testemunha com 
teor de proteína de $21 \%$ e outras quatro dietas com teor de $17 \%$ de $\mathrm{PB}$ e teores de glicina + serina total de 1,50; 1,75; 2,00 e 2,25\% (Tab. 1). Essas dietas, suplementadas com aminoácidos essenciais de acordo com as exigências descritas por Rostagno et al. (2005), foram fornecidas à vontade durante todo o período experimental.

Os frangos foram pesados aos 21, 28 e 35 dias de idade, e o ganho de peso foi calculado para cada fase do crescimento. O consumo de dieta foi determinado subtraindo-se da quantidade ofertada a sobra da dieta ao final de cada fase de criação. Para o cálculo do consumo da dieta, foi considerado o número de aves mortas na semana. O cálculo de conversão alimentar foi feito a partir do consumo médio de ração, e o ganho médio de peso das aves ao final do experimento. O cálculo da conversão alimentar foi corrigido levando-se em conta a mortalidade ocorrida durante a semana, segundo Sakomura e Rostagno (2007). O número de aves mortas foi registrado diariamente; a partir desses dados, determinou-se a porcentagem de mortalidade e, posteriormente, foi calculada a taxa de viabilidade (100 menos a porcentagem de mortalidade).

Aos 35 dias de idade, foram amostrados aleatoriamente quatro frangos por repetição para avaliação da carcaça. Antes do abate, os frangos, submetidos a jejum de dieta de 12 horas e identificação individual, foram pesados. Os procedimentos de abate foram os mesmos adotados em um abatedouro industrial, de acordo com as normas do SIF, porém as aves não passaram pelo chiller para que não houvesse interferência na composição de carcaça em razão da absorção de água.

A avaliação do rendimento de carcaça e cortes foi feita considerando-se o peso da carcaça limpa e eviscerada (com pés, cabeça e pescoço) em relação ao peso vivo em jejum obtido antes do abate. Na avaliação dos demais cortes (coxa + sobrecoxa, peito, dorso, asa), o rendimento foi considerado em relação ao peso da carcaça eviscerada. Após a avaliação do rendimento, cada carcaça, sem as vísceras e moída em moedor de carne, foi homogeneizada, e dela foram retiradas amostras que foram conservadas $\mathrm{a}-12^{\circ} \mathrm{C}$.
Em razão da alta concentração de água e gordura na carcaça, as amostras foram submetidas, inicialmente, à pré-secagem em estufa com ventilação forçada a $60^{\circ} \mathrm{C}$, por 96 horas, seguida de pré-desengorduramento pelo método a quente, por quatro horas, em extrator tipo "Soxhlet". As amostras pré-secas e pré-desengorduradas foram, então, moídas e acondicionadas em potes de plástico, para análises posteriores. A água e a gordura retiradas durante o preparo inicial das amostras foram consideradas para correções dos valores das análises subsequentes. As análises de matéria seca, proteína bruta e extrato etéreo das amostras foram realizadas de acordo com Silva (1990).

O delineamento experimental foi inteiramente ao acaso, com cinco tratamentos e cinco repetições, sendo cada repetição composta de 30 aves para avaliação do desempenho. Para avaliação dos rendimentos de carcaça inteira, partes da carcaça (coxa + sobrecoxa, peito, dorso, asa), consideraram-se quatro aves por repetição. Os dados foram submetidos à análise de variância, e os resultados obtidos com as dietas de baixos níveis proteicos com diferentes níveis de glicina+serina foram comparados à dietacontrole pelo teste Dunnett. As análises dos dados foram feitas por meio do programa SAEG (Sistema..., 2007).

Para avaliação apenas dos efeitos dos níveis de glicina+serina sobre o desempenho e os rendimentos de carcaça inteira e partes da carcaça, adotou-se o delineamento experimental com quatro tratamentos - eliminou-se o tratamento-controle - e cinco repetições, sendo o número de aves por repetição o mesmo mencionado anteriormente para as características de desempenho e aquele para as características de carcaças. Nestes casos, os efeitos significativos dos níveis de glicina+serina sobre a característica analisada foram calculados por análise de regressão, sendo que os graus de liberdade dos fatores foram desdobrados em seus componentes linear e quadrático para a escolha do modelo de regressão que melhor descrevesse as observações. 
Tabela 1. Composição percentual e valores nutricionais calculados das dietas com níveis reduzidos de PB na fase de crescimento

\begin{tabular}{|c|c|c|c|c|c|}
\hline Ingrediente & $\mathrm{T} 1$ & $\mathrm{~T} 2$ & $\mathrm{~T} 3$ & $\mathrm{~T} 4$ & T5 \\
\hline Milho & 55,91 & 55,91 & 55,91 & 55,91 & 55,91 \\
\hline Farelo de soja & 35,86 & 25,90 & 25,90 & 25,90 & 25,90 \\
\hline Óleo de soja & 4,67 & 4,67 & 4,67 & 4,67 & 4,67 \\
\hline Amido & - & 5,57 & 5,57 & 5,57 & 5,57 \\
\hline Calcário & 0,835 & 0,835 & 0,835 & 0,835 & 0,835 \\
\hline Fosfato bicálcico & 1,68 & 1,78 & 1,78 & 1,78 & 1,78 \\
\hline Sal comum & 0,432 & 0,437 & 0,437 & 0,437 & 0,437 \\
\hline Inerte & - & 3,48 & 3,23 & 3,00 & 2,72 \\
\hline Premix vit. mineral ${ }^{1}$ & 0,4 & 0,4 & 0,4 & 0,4 & 0,4 \\
\hline DL-Metionina & 0,181 & 0,293 & 0,293 & 0,293 & 0,293 \\
\hline L-Lisina & 0,024 & 0,351 & 0,351 & 0,351 & 0,351 \\
\hline L-Treonina & - & 0,127 & 0,127 & 0,127 & 0,127 \\
\hline L-Arginina & - & 0,075 & 0,075 & 0,075 & 0,075 \\
\hline L-Isoleucina & - & 0,058 & 0,058 & 0,058 & 0,058 \\
\hline L-Valina & - & 0,096 & 0,096 & 0,096 & 0,096 \\
\hline L-Triptofano & - & 0,002 & 0,002 & 0,002 & 0,002 \\
\hline L- Glicina & - & - & 0,254 & 0,506 & 0,759 \\
\hline Total & 100 & 100 & 100 & 100 & 100 \\
\hline \multicolumn{6}{|c|}{ Composição calculada } \\
\hline Proteína bruta (\%) & 21 & 17 & 17 & 17 & 17 \\
\hline EMA (kcal/kg) & 3120 & 3120 & 3120 & 3120 & 3120 \\
\hline Cálcio (\%) & 0,84 & 0,84 & 0,84 & 0,84 & 0,84 \\
\hline Fósforo disp. (\%) & 0,42 & 0,42 & 0,42 & 0,42 & 0,42 \\
\hline Lisina dig. (\%) & 1,05 & 1,05 & 1,05 & 1,05 & 1,05 \\
\hline Met. + Cis. dig. (\%) & 0,76 & 0,76 & 0,76 & 0,76 & 0,76 \\
\hline Treonina dig. (\%) & 0,71 & 0,68 & 0,68 & 0,68 & 0,68 \\
\hline Triptofano dig. (\%) & 0,23 & 0,18 & 0,18 & 0,18 & 0,18 \\
\hline Isoleucina dig. (\%) & 0,83 & 0,70 & 0,70 & 0,70 & 0,70 \\
\hline Valina dig. (\%) & 0,89 & 0,79 & 0,79 & 0,79 & 0,79 \\
\hline Arginina dig. (\%) & 1,35 & 1,10 & 1,10 & 1,10 & 1,10 \\
\hline Fenil.+Tir. dig. (\%) & 1,64 & 1,28 & 1,28 & 1,28 & 1,28 \\
\hline Gli + Ser. total (\%) & 1,92 & 1,50 & 1,75 & 2,00 & 2,25 \\
\hline
\end{tabular}

${ }^{1}$ Suplemento vitamínico-mineral - composição por Kg: vit A(UI) 2.000.000; vit D3(UI)375.000; vit E (mg) 3.750; vit B1(mg) 250; vit B2 (mg) 750; vit B6 (mg) 500; vit B12 (mcg) 3750; niacina (mg) 6250; ac. pantotênico (mg) 2500; biotina (mg) 10; ac. fólico (mg) 125mg; colina (mg) 75000; selênio (mg) 45; iodo (mg) 175; ferro (mg) 12525; cobre (mg) 2.500; manganês (mg) 19.500; zinco (mg) 13.750; avilamicina (mg) 15.000; narasin (mg) 12.250; BHT (mg) 500. T1: sem adição de gli+ser; T2: 1,75\% de gli+ser; T3: 2,0\% de gli+ser; T4: 2,25\% gli+ser; T5: 1,50\% de gli+ser.

\section{RESULTADOS E DISCUSSÃO}

Os resultados de desempenho dos frangos dos 22 aos 35 dias de idade constam na Tab. 2. Não houve efeito do teor de gli+ser sobre o ganho de peso, peso aos 35 dias e consumo de dieta. Os tratamentos de menor teor de $\mathrm{PB}$, suplementados com gli+ser, também não diferiram da dietacontrole em nenhuma das variáveis de desempenho avaliadas, e em relação à conversão alimentar, as aves responderam de maneira linear à suplementação de L-glicina. 
Tabela 2. Desempenho de frangos de corte de 22 a 35 dias de idade, alimentados com dietas que continham diferentes níveis de gli+ser total e baixo nível de PB em relação à dieta-controle

\begin{tabular}{ccccc}
\hline Teor de gli+ser (\%) & $\begin{array}{c}\text { Peso aos 35 dias } \\
(\mathrm{kg})\end{array}$ & $\begin{array}{c}\text { Ganho peso aos } \\
\text { 35dias }(\mathrm{kg})\end{array}$ & $\begin{array}{c}\text { Consumo dieta } \\
(\mathrm{kg})\end{array}$ & $\begin{array}{c}\text { Conversão } \\
\text { alimentar*1 }^{*}\end{array}$ \\
\hline 1,50 & 2,21 & 1,29 & 2,67 & 2,06 \\
1,75 & 2,24 & 1,32 & 2.66 & 2,02 \\
2,00 & 2,21 & 1,29 & 2.63 & 2,03 \\
2,25 & 2,22 & 1,30 & 2,61 & 1,99 \\
\hline 1,92(Controle) & 2,22 & 1,30 & 2,65 & 2,04 \\
\hline CV (\%) & 1,88 & 3,29 & 2,93 & 2,94 \\
\hline
\end{tabular}

${ }^{1}$ Efeito linear do teor de gli+ser $(\mathrm{P}<0,05): \hat{\mathrm{Y}}=2,16022-0,069880 \mathrm{X}\left(\mathrm{R}^{2}=0,72\right)$.

${ }^{*}$ Não houve diferença entre aves alimentadas com dieta basal (17\% PB) que continha diferentes teores de gli+ser e de aves alimentadas com dieta-controle (21\% PB), pelo teste Dunnet $(\mathrm{P}>0,05)$.

Vários autores relataram queda no desempenho de frangos de corte na fase de crescimento alimentados com dietas que continham baixos teores de PB (Sabino et al. 2004; Rigueira et al., 2006; Namroud et al., 2008). Porém, de acordo com os resultados obtidos e nas condições em que o experimento foi realizado, vê-se que foi possível reduzir o teor de $\mathrm{PB}$ das dietas de frangos de corte para $17 \%$ na fase de crescimento sem que houvesse prejuízos sobre as variáveis de desempenho.

Com o objetivo de verificar possíveis efeitos da suplementação de aminoácidos não essenciais em dietas de baixa PB, Kerr e Kidd (1999) encontraram melhoria na conversão alimentar de frangos de corte na fase de crescimento e que foram alimentados com dieta de baixa PB suplementada com ácido glutâmico. Porém, segundo os autores, a melhora não foi suficiente para igualar o desempenho com a dieta-controle. Apesar da importância nutricional da glicina para as fases iniciais de criação das aves, a partir dos resultados do presente trabalho em relação à conversão alimentar, verificou-se que a suplementação de L-glicina teve efeito também na fase de crescimento.
Dionízio (2005), ao trabalhar com uma dieta de $18 \%$ de PB suplementada com glicina para frangos de corte dos 21 aos 42 dias, observou que a suplementação permitiu conversão alimentar e ganho de peso similares aos das aves alimentadas com dieta-controle (20\% PB). Da mesma forma, Aletor et al. (2000), ao suplementarem dietas de reduzido teor proteico com aminoácidos não essenciais, também verificaram melhora na conversão alimentar de frangos dos 21 aos 42 dias de idade.

Em relação ao consumo de dieta, de maneira semelhante aos resultados deste trabalho, Sabino et al. (2004), Rigueira et al. (2006) e Oliveira et al. (2007) não observaram efeito do teor de PB sobre o consumo de dieta. Por outro lado, Aletor et al. (2000), Costa et al. (2001) e Kamram et al. (2008) verificaram maior consumo com a redução da $\mathrm{PB}$ das dietas. De acordo com Silva et al. (2001) e Namroud et al. (2008), a diminuição do teor de $\mathrm{PB}$ levou à diminuição no consumo da dieta.

Não houve efeito de tratamento sobre a viabilidade (Tab.3) ao se compararem as dietas com diferentes teores de gli+ser e a dietacontrole.

Tabela 3. Viabilidade (\%) de aves de 21 a 35 dias de idade que receberam dietas com diferentes teores de glicina+serina

\begin{tabular}{ccc}
\hline Teor de gli+ser $(\%)$ & Viabilidade $(\%)^{*}$ & CV (\%) \\
\hline 1,50 & 98,00 & \\
1,75 & 99,33 & 1,65 \\
2,00 & 99,33 & \\
2,25 & 99,33 & \\
\hline Controle & 98,00 & \\
\hline
\end{tabular}

${ }^{*}$ Não houve diferença entre a viabilidade de aves alimentadas com dieta basal (17\% PB) que continha diversos teores de gli+ser e de aves alimentadas com dieta-controle (21\%PB), pelo teste Dunnet $(\mathrm{P}>0,05)$. 
Os resultados de rendimentos de carcaça e de cortes de frangos de corte constam na Tab. 4. Não houve efeito do teor de glicina sobre o rendimento de carcaça, rendimento de coxa, asas e dorso, e não se observou diferença entre tratamentos quanto ao desempenho das aves. No caso de rendimento de carcaça e cortes, nas condições deste experimento, o teor de PB pode ser reduzido para $17 \%$, desde que suplementado com gli+ser.

Os rendimentos de carcaça e cortes de frangos não diferiram quando as aves foram alimentadas com diferentes níveis de $\mathrm{PB}$ de acordo com os resultados de Costa et al. (2001), Faria Filho et al. (2006), Rigueira et al. (2006) e Kamran et al. (2008) encontraram efeito linear crescente para rendimento de peito de frangos de corte alimentados com dietas cujos conteúdos de PB variaram de 17,5 a 19,5\% de PB. Também Sabino et al. (2004) verificaram efeito linear para rendimento de carcaça com o aumento do teor de
PB. De acordo com Leeson (1995), à medida que há incremento da ingestão proteica, em razão do maior conteúdo de proteína da dieta, há aumento do rendimento de peito.

Isso não ocorreu neste experimento provavelmente pelo fato de as aves terem sido abatidas aos 35 dias de idade. Pode não ter havido tempo suficiente para o aparecimento do efeito do tratamento sobre o rendimento de cortes ou o nível de PB para máximo rendimento de carcaça e cortes não ter sido utilizado.

Aves alimentadas com dietas com menor teor proteico $(17 \% \mathrm{~PB})$, contendo diferentes níveis de gli+ser, apresentaram os mesmos rendimentos que aves alimentadas com a dieta-controle (21\% PB), sem suplementação. Assim, pode ser justificada a redução de quatro pontos percentuais no teor de proteína, em dietas com $1,5 \%$ de gli+ser, desde que sejam formuladas sob conceito de proteína ideal.

Tabela 4. Rendimento percentual de carcaça e cortes de frangos de corte aos 35 dias de idade alimentados com dietas que continham diferentes teores de gli+ser total e baixo teor de proteína bruta em relação à dieta-controle

\begin{tabular}{cccccc}
\hline $\begin{array}{c}\text { Teor de gli+ser. } \\
(\%)\end{array}$ & $\begin{array}{c}\text { Rend. } \\
\text { carcaça(\%) }\end{array}$ & $\begin{array}{c}\text { Rend. } \\
\text { peito(\%) }\end{array}$ & $\begin{array}{c}\text { Rend. coxa } \\
(\%)^{1^{*}}\end{array}$ & $\begin{array}{c}\text { Rend. asas } \\
(\%)^{1^{*}}\end{array}$ & $\begin{array}{c}\text { Rend. dorso } \\
(\%)^{1^{*}}\end{array}$ \\
\hline 1,50 & 77,71 & 34,07 & 31,32 & 10,65 & 9,89 \\
1,75 & 78,57 & 34,41 & 30,50 & 10,80 & 9,74 \\
2,00 & 77,46 & 34,96 & 30,43 & 10,83 & 8,96 \\
2,25 & 78,24 & 34,55 & 30,29 & 10,73 & 9,67 \\
\hline 1,92 Controle) & 78,82 & 34,68 & 30,32 & 10,78 & 9,31 \\
CV $(\%)$ & 1,90 & 4,57 & 7,67 & 11,01 & 8,03 \\
\hline
\end{tabular}

*Efeito não significativo do teor de gli+ser $(\mathrm{P}>0,05)$

${ }^{1}$ Não houve diferença entre rendimentos das aves alimentadas com dieta basal (17\% PB) que continha diversos teores de gli+ser e de aves alimentadas com dieta-controle (21\% PB), pelo teste Dunnet $(\mathrm{P}>0,05)$.

Os dados de composição de carcaça de frangos encontram-se na Tab. 5. Houve efeito linear decrescente dos níveis de gli+ser sobre o teor de matéria seca das carcaças. Os resultados de proteína bruta, extrato etéreo e matéria mineral não apresentaram diferenças significativas. Da mesma forma, ao se compararem esses resultados com os da dieta-controle, verifica-se que não houve efeito dos tratamentos sobre as variáveis de composição de carcaça. Esperava-se maior deposição de gordura na carcaça com a diminuição do teor de proteína bruta, fato que não ocorreu. Uma possível explicação poderia ser a alta taxa de deposição proteica das aves na idade em que foram abatidas.
Furlan et al. (2004) relataram que, em aves mantidas sobre estresse de calor, os teores de extrato etéreo do peito e da coxa não se alteraram com a redução proteica. Diversos trabalhos da literatura verificaram aumento no teor de gordura na carcaça com diminuição da proteína. Aletor et al. (2000) observaram aumento no teor de gordura na carcaça de frangos de corte alimentados com dietas que continham teores mais baixos de PB. Aumento na porcentagem de gordura na carcaça de animais alimentados com dietas de baixo teor de proteína também foi encontrado por Tuitoek et al. (1997), Braga (1999), Silva et al. (2003) e Gonzalez-Esquera e Leeson (2005). 
Tabela 5. Composição percentual na matéria seca da carcaça de frangos de corte aos 35 dias de idade alimentados com dietas com diferentes níveis de gli+ser total e que continham teores reduzidos de proteína bruta

\begin{tabular}{ccccc}
\hline Teor de gli+ser (\%) & $\begin{array}{c}\text { Matéria } \\
\text { seca }(\%)^{2}\end{array}$ & $\begin{array}{c}\text { Proteína bruta } \\
(\%)^{1}\end{array}$ & Extrato etéreo $^{1^{*}}$ & Matéria mineral $^{1^{*}}$ \\
\hline 1,50 & 41,56 & 23,56 & 14,89 & 3,35 \\
1,75 & 41,21 & 23,45 & 14,56 & 3,64 \\
2,00 & 40,69 & 23,00 & 14,26 & 3,52 \\
2,25 & 40,11 & 22,57 & 14,34 & 3,31 \\
\hline 1,92 Controle) & 41,79 & 24,35 & 14,09 & 3,74 \\
CV (\%) & 2,62 & 3,78 & 12,00 & 10,89 \\
\hline
\end{tabular}

${ }^{1}$ Efeito não significativo do teor de gli+ser. $(\mathrm{P}>0,05)$.

${ }^{2}$ Efeito linear do teor de gli+ser $(\mathrm{P}<0,05)$ : $\mathrm{Y}=44,5201-1,93532 \mathrm{X}\left(\mathrm{R}^{2}=0,99\right)$

*Não houve diferença na composição percentual na matéria seca das aves alimentadas com dieta basal (17\% PB) contendo diversos teores de gli+ser e a das aves da dieta-controle ( $21 \% \mathrm{~PB})$, pelo teste Dunnet $(\mathrm{P}>0,05)$.

Aletor et al. (2000) verificaram que aves alimentadas com dietas com baixo nível proteico, em relação à porcentagem de proteína depositada na carcaça, não apresentaram diferenças significativas comparadas às aves alimentadas com dieta-controle. De acordo com Furlan et al. (2004), a deposição de aminoácidos na carcaça é preestabelecida de acordo com a informação genética da ave. Porém, Gonzalez-Esquera e Leeson (2005) observaram aumento na deposição de proteína na carcaça de aves alimentadas com dietas mais ricas em proteína, fato que também ocorreu no presente experimento, ao se comparar a dieta-controle com os tratamentos com 2,00 e $2,25 \%$ de glicina+serina total em dieta de $17 \%$ de proteína bruta.

\section{CONCLUSÕES}

Os teores de glicina+serina melhoram de maneira linear a conversão alimentar, assim é possível reduzir o teor de $\mathrm{PB}$ da dieta de frangos de corte de 21 a 35 dias de idade em quatro pontos percentuais, desde que seja utilizado o conceito de proteína ideal na formulação da dieta.

\section{REFERÊNCIAS BIBLIOGRÁFICAS}

ALETOR, V.A.; HAMID, I.I.; NIEB, E. et al. Low-protein amino acid-supplemented diets in broiler chickens: effects on performance, carcass characteristics, whole-body composition and efficiencies of nutrient utilisation. J. Sci.Food Agric., v.80. p.547-554, 2000.
BRAGA, J.P. Proteína ideal para frangos de corte: efeito sobre o desempenho e composição de carcaça. 1999. 25f. Dissertação (Mestrado em Zootecnia) - Escola de Veterinária, Universidade Federal de Minas Gerais, Belo Horizonte, MG.

BREGENDAHL, K.; SELL, J.L.; ZIMMERMAN, DR. Effect of low-protein diets on growth performance and body composition of broiler chicks. Poult. Sci., v.81. p.1156-1167, 2002.

COSTA, F.G.P.; ROSTAGNO, H.S.;. ALBINO, L.F.T. et al. Níveis dietéticos de proteína bruta para frangos de corte de um a 21 e 22 a 42 dias de idade. Rev. Bras. Zootec., v.30, p.1498-1505, 2001.

DEAN, D.W.; BIDNER, T.D.; SOUTHERN, L.L. Glycine supplementation to low protein, amino acid-suplemented diets supports optimal performance of broiler chicks. Poult. Sci., v.85, p.288-296, 2006.

DIONIZIO, M.A. Níveis proteicos e suplementação aminoacídica na dieta de frangos de corte na fase de crescimento. 2005. 106f. Tese (Doutorado) - Universidade Federal de Viçosa, Viçosa, MG.

FARIA FILHO, D.E.; ROSA, P.S.; FIGUEIREDO, D.F. et al. Dietas de baixa proteína no desempenho de frangos criados em diferentes temperaturas. Pesqui. Agropecu. Bras., v.41, p.101-106, 2006.

FURLAN, R.L.; FARIA FILHO, D.E.; ROSA, P.S. et al. Does low-protein diet improve broiler performance under heat stress conditions? Rev. Bras. Cienc. Avic., v.6, p.71-79, 2004. 
GONZALEZ-ESQUERRA， R.; LEESON， S Effects of acute versus chronic heat stress on broiler response to dietary protein. Poult. Sci., v.84, p.1562-1569, 2005.

KAMRAN, Z.; SARWAR,M.; NISA, M. et al. Effect of low-protein diets having constant energy-to-protein ratio on performance and carcass characteristics of broiler chickens from one to thirty-five days of age. Poult. Sci., v.87, p.468-474, 2008.

KERR, B.J.; KIDD, M.T. Amino acid supplementation of low - protein broiler diets 2 . Formulation on an ideal amino acid basis. $J$. Appl. Poult. Res., v.8, p. 310-320, 1999.

LEESON, S. Nutrição e qualidade da carcaça de frangos de corte. In: CONFERÊNCIA APINCO DE CIÊNCIA E TECNOLOGIA AVÍCOLAS, 1995, Curitiba. Anais... Campinas: FACTA, 1995. p.118-123.

NAMROUD, N.F.; SHIVAZAD, M.; ZAGHARI, M. Effects of fortifying low crude protein diet with crystalline amino acids on performance, blood ammonia level, and excreta characteristics of broiler chicks. Poult. Sci., v.87, p.2250-2258, 2008.

OLIVEIRA, W.P.; OLIVEIRA, R.F.M.; DONZELE, J.L. et al. Níveis de proteína bruta com suplementação de aminoácidos na ração de frangos de corte submetidos ao estresse de calor. In: REUNIÃO ANUAL DA SOCIEDADE BRASILEIRA DE ZOOTECNIA, 44., 2007, Jaboticabal, SP. Anais... Jaboticabal: Sociedade Brasileira de Zootecnia, 2007.

RIGUEIRA, L.C.M.; ROSTAGNO, H.S.; ALBINO, L.F.T. et al. Aplicação do conceito de proteína ideal em dietas com diferentes níveis proteicos para frangos de corte no período de 21 a 35 dias de idade. In: REUNIÃO ANUAL DA SOCIEDADE BRASILEIRA DE ZOOTECNIA, 43., 2006, João Pessoa. Anais... João Pessoa: Sociedade Brasileira de Zootecnia, 2006.
ROSTAGNO, H.S.; ALBINO, L.F.T.; DONZELA, J.L. et al. Tabelas brasileiras para aves e suínos. Composição de alimentos $\mathrm{e}$ exigências nutricionais. 2.ed. Viçosa: UFV, 2005. 186p.

SABINO, H.F.N.; SAKOMURA, N.K.; NEME, R. et al. Níveis proteicos na ração de frangos de corte na fase de crescimento. Pesqui. Agropecu. Bras., v.39, p.407-412, 2004

SISTEMAS de análises estatísticas e genéticas. SAEG. Versão 9.1. Viçosa: UFV, 2007.

SAKOMURA, N.K.; ROSTAGNO, H.S. Métodos de pesquisa em nutrição de monogástricos. Jaboticabal: Funep, 2007. 283p.

SILVA, D.J. Análise de alimentos: métodos químicos e biológicos. 2.ed. Viçosa, MG: UFV, 1990. 166p.

SILVA, J.H.V.; ALBINO, L.F.T.; NASCIMENTO, A.H. Níveis de energia e relações energia:proteína para frangos de corte de 22 a 42 dias de idade. Rev. Bras. Zootec., v.30, p.1791-1800, 2001.

SILVA, J.H.V.; ALBINO, L.F.T.; NASCIMENTO, A.H. Estimativas da composição anatômica da carcaça de frangos de corte com base no nível de proteína da ração e peso da carcaça. Rev. Bras. Zootec., v.32, p.344352, 2003.

TEJEDOR, A. Exigências nutricionais de met + cist, de treonina e de arginina para frangos de corte nas diferentes fases de criação. 2002. 118f. Tese (Doutorado) - Universidade Federal de Viçosa, Viçosa, MG.

TUITOEK, K.; YOUNG, L.G.; de LANGE, C.F.M. et al. The effect of reducing excess dietary amino acids on growing-finishing pig performance: An evaluation of the ideal protein concept. J. Anim. Sci., v.75, p.1575-1583, 1997. 